\title{
Crises, Investments, and Political Institutions
}

\section{Per F. Andersson and Johannes Lindvall}

\section{Abstract}

On the basis of a game-theoretic model, this paper argues that governments typically manage crises more effectively in systems where political power is concentrated in a single party, but they are more likely to make investments in future welfare in systems where political power is shared among several parties. The paper makes two contributions. First of all, it shows that both crisismanagement failures and investment failures can be explained by a common mechanism: an intertemporal commitment problem that arises from the inability of political agents to commit to future policy choices. Second, it shows that power-sharing institutions are often associated with more effective government than power-concentration institutions, in contrast to much of the normative literature in comparative politics, in which power-sharing institutions are often justified on other grounds, such as representativeness, responsiveness, or social cohesion. In a world where crises dominate, power-concentration institutions typically perform better; in a world where investment problems dominate, power-sharing institutions do.

Keywords: crises, investments, constitutions, commitment

Accepted for publication in the Journal of Theoretical Politics on June 8, 2018. 
Governments sometimes confront urgent problems that require them to adopt new policies swiftly to avoid harm. At other times, governments confront long-term problems, requiring them to take costly actions to increase future welfare. When they deal with the first type of problem, governments engage in "crisis management." When they deal with the second type of problem, governments make "political investments."

On the basis of a simple game-theoretic model, this paper argues that governments often manage crises more effectively in systems where political power is concentrated in a single party, but they are more likely to make investments in systems where power is shared more widely. In other words, whereas the "majoritarian" vision of democracy is typically associated with more effective crisis management, the "proportional" vision is associated with better long-term policies. ${ }^{2}$

Our paper makes two contributions. First, we show that both crisis-management failures and investment failures can be explained by a common mechanism: an inter-temporal commitment problem that arises from the inability of political agents to commit to future policies. Second, we show that power-sharing institutions are often associated with more effective government than power-concentration institutions, in contrast to much of the normative literature in comparative politics, where power-sharing institutions are justified on other grounds, such as representativeness, responsiveness, or social cohesion. ${ }^{3}$

The most important implication of the paper's argument is that constitution-making involves a crucial trade-off: institutions that enable governments to respond to crises are typically inferior when it comes to solving long-term political problems, and vice versa. The optimal constitution is therefore context-specific. In a world where crises dominate, power-concentration institutions

\footnotetext{
${ }^{1}$ Jacobs $(2016,434-435)$ defines political investments as "policies that make welfare tradeoffs at the expense of the present and in favor of the future," exchanging "a given amount of short-run welfare" for "greater long-run welfare." ${ }^{2}$ On the "majoritarian" and "proportional" visions of democracy, see Powell (2000).

${ }^{3}$ For a discussion, see Lindvall (2017, Chapter 1).
} 
often perform better, but in a world where investment problems dominate, power-sharing institutions are superior. The precise nature of this trade-off depends on the other parameters of our model, notably the level of political polarization and the magnitude of the policy changes that are required to avert a crisis. Interestingly, for some parameter values, power-sharing institutions perform better in both worlds.

\section{Crises and Investments}

According to an important literature in political science, governments may become unable to respond effectively to changes in the economic, social, and political environment if political power is shared among several parties. George Tsebelis $(2002,443)$ has argued, for instance, that having many "veto players" leads to high "policy stability," making "the change of even an undesirable status quo difficult." According to another important literature, however, concentrating power in a single party may itself have pernicious consequences, since the possibility of opportunistic behavior by future governments renders governments unwilling to make policy changes that have short-term costs. Besley and Persson (2011) argue, for instance, that more inclusive political institutions increase the likelihood that governments invest in "state capacity" (the capacity to collect revenue and protect property rights).

Our message is that the first of these ideas is correct when governments confront crises, but the second idea is correct when governments deal with long-term political investment problems.

The main intuition behind the first part of our analysis, which deals with crisis management, is that political conflicts in times of crisis are more difficult to resolve in power-sharing systems since there is a high likelihood that policies adopted for short-term reasons are "locked in." The basic mechanism is a commitment problem: since the party that benefits the most from a shift in policy 
cannot commit to reversing that policy once the crisis is over, it may be rational for other parties to block effective policy adjustments.

The main intuition behind the second part of our analysis, which deals with political investments, is that opportunistic behavior by future governments is less likely in power-sharing systems than in power-concentration systems. Like crisis management, investments are associated with an inter-temporal commitment problem: if the opposition party or parties cannot commit to future policies, the governing party has reason to fear that it will no longer be in a position to reap the benefits of the investment when those benefits are realized. Power sharing can be seen as an institutional solution to this inter-temporal decision problem, since both present and future power tend to be shared more widely in power-sharing systems.

We are not the first to examine the relationship between political institutions and crisis management, nor are we the first to examine the relationship between political institutions and investments. For example, our argument about crisis management has a lot in common with the theoretical and empirical literatures on fiscal stabilization and financial crises (see especially Alesina and Drazen 1991 and MacIntyre 2001) and with the recent literature on policymaking with an endogenous status quo (Dziuda and Loeper 2016, 2017). ${ }^{4}$ Our model of investments, meanwhile, has a lot in common with the model of state capacity developed by Besley and Persson (2011), and with Alan Jacobs’s analysis of "governing for the long term” (2011).

But studying government responses to crises and investment problems in a single modeling framework, as we do, has several advantages.

\footnotetext{
${ }^{4}$ More generally, the idea that "non-majoritarian" democracies tend to be overburdened by "[c]hallenges requiring swift response" (Schmidt 2002, 150) has long been debated by comparative politics scholars such as Lijphart (1977, 2012) and Sartori (1987).
} 
Most importantly, we identify a common mechanism in both parts of our model: an intertemporal commitment problem that arises from the inability of political agents to commit to future policies. That idea distinguishes our argument from related models. The ineffectiveness of powersharing when governments face crises is often explained with reference to the high transaction costs that come with political bargaining. ${ }^{5}$ We get to a similar conclusion without making any assumptions about political transaction costs, which are notoriously hard to quantify. ${ }^{6}$ Meanwhile, the future-orientedness of governments in power-sharing democracies is often explained with reference to their capacity for deliberation and the exercise of reasoned and considered judgment (see especially Lijphart 2012). We get to a similar conclusion without making any assumptions about policymaking styles.

Moreover, studying government responses to crises and investment problems within a single modeling framework leads to a more balanced assessment of the relative advantages and disadvantages of power-sharing institutions. For reasons that will become clear later on, we caution against any across-the-board negative or positive assessments of particular institutions, for in our model, the net effect of institutions depends on whether countries are more likely to experience crises or investment problems, on political polarization, and on the magnitude of the policy changes that are needed to avert crises.

Some scholars have highlighted the difficulty of committing to future policies and others have emphasized the drawbacks of policy rigidity, but few scholars have integrated both aspects of policymaking in a single model. One prominent exception is Tommasi, Scartascini, and Stein (2014), which investigates "stability" and "adaptability" in a repeated-games framework. They

\footnotetext{
${ }^{5}$ For example, Schmidt (2002) attributes the greater effectiveness of majoritarian democracies to the "rapid development of political alternatives and rapid decision making."

${ }^{6}$ This also sets our paper apart from Lindvall (2017, Chapter 3 and Chapter 5).
} 
show that in an inter-temporal model, having more veto players lead to more stability, but also to more adaptability. ${ }^{7}$ The argument is that more veto players today means more veto players in the future, changing the expectations of political agents and sustaining cooperative equilibria over time. Our model differs from the Tommasi, Scartascini, and Stein model in two important respects. First of all, our approach does not rely on cooperation enforced by repeated interaction; second, we are interested in two different types of policy changes - crisis-management and investments - and not primarily in the trade-off between stability and change. ${ }^{8}$

\section{The Model}

Consider a society that is made up of two groups of citizens. Each group is represented by a political party, denoted $J=A, B$, which acts in the interest of the members of the group.

The government sets a single policy, which is defined by the parameter $\pi \in[0,1]$. The benefits that citizens, and indirectly therefore also parties, derive from this policy depends on two factors: the distance between the policy that is adopted by the government and their own ideal policy, $\pi_{J}^{*}$, and the policy's "quality," which is defined by the parameter $\omega$. Parties may disagree on the level

\footnotetext{
${ }^{7}$ For a related argument about how another important aspect of policy-making - lobbying costs - vary with the number of veto players, see Gehlbach and Malesky (2010).

${ }^{8}$ Our argument is also closely related to the literature on how commitment problems and uncertainty about the future lead to the "inefficient use of power" (Powell 2004). In this family of models, sub-optimal political decisions such as bureaucratic insulation (de Figueiredo Jr. 2002), coups (Acemoglu and Robinson 2000, 2001), wars (Fearon 1995), and civil wars (Fearon 2004), are interpreted as actions that insure against the possibility of a future decline in power. There are precursors to our argument that these sorts of effects are more pronounced the more power is concentrated. For example, sharing power more widely through democratization has been shown to mitigate the negative effects of large shifts in relative power (Ghosal and Proto 2009), and in a democratic context, Alesina and Tabellini (1990) explore a two-party model in which the party in power uses the level of debt strategically to influence the choices of the next government (the level of debt becoming inefficiently high when polarization is high and the probability of re-election is low). Moreover, our paper is related to recent analyses of dynamic policymaking with an endogenous status quo, in which uncertainty over the preferences of future governments affects the decisions that parties or legislators make today. For example, in Buisseret and Bernhardt (2017), the expectation of future gridlock makes players use their power to maximum effect today, whereas the expectation of a better possible deal in the future makes them wait. Similarly, in Dziuda and Loeper (2016), a player takes more extreme positions in the short-run as a form of insurance against future shifts in power.
} 
of $\pi$, but they all have an interest in keeping policy quality high. For example, whereas parties typically have different preferences over the level of public-goods provision, they have a shared interest in public goods being provided as efficiently as possible. ${ }^{9}$

To keep things simple, we examine a two-period model and we assume that the utility citizens represented by party $J$ derive from government policy in period $t=1,2$ is defined by

$$
U_{J, t}=\left(1-\left(\pi_{t}-\pi_{J}^{*}\right)^{2}\right) \omega_{t}
$$

where $\pi_{J}^{*}$ is party $J$ 's ideal policy and $\omega_{t}$ is the quality of the policy in period $t$. The intuition behind this functional form is simple. If $\pi_{t}=\pi_{J}^{*}$ (that is, if party $J$ 's ideal policy is implemented in period $t$ ), group $J$ 's utility attains its maximum value, $\omega_{t}$. If, on the other hand, $J$ would prefer a policy that is the complete opposite of the policy that is adopted by the government, $J$ 's utility is 0 . Between these two extreme values, $J$ 's utility decreases at an increasing rate as the distance between $J$ 's ideal policy and the actual policy increases. Note that although $J$ cares relatively more about policy quality if it approves of the government's policy for ideological reasons, the policy's quality only ceases to matter entirely to $J$ if $J$ is completely opposed to the policy adopted by the government.

\footnotetext{
${ }^{9}$ For one example of what $\pi$ and $\omega$ might mean in practice, consider the following scenario. Assume that citizens, and indirectly therefore also parties, derive utility from two public goods, $g_{a}$ and $g_{b}$, but have different preferences over those goods, in the sense that some citizens would like to devote more resources to one good than to the other, and vice versa. The parameter $\pi$ might then describe the proportion of the government's resources that is devoted to $g_{a}$ (the proportion $1-\pi$, consequently, being devoted to $g_{b}$ ). In this scenario, the quality parameter $\omega$ can be used to describe the total volume of resources available for spending on $g_{a}$ and $g_{b}$, or, alternatively, the efficiency of the delivery of $g_{a}$ and $g_{b}$ (so that a higher level of $\omega$ enhances the welfare effect of a given level of spending on $g_{a}$ and $g_{b}$ ). But $\pi$ and $\omega$ can also be interpreted differently, as we discuss in Section 6 - the general idea is that it is possible to distinguish between elements of public policy that different groups disagree on $(\pi)$ and elements of public policy that all are typically in favor of $(\omega)$.
} 
Without loss of generality, we assume that $\pi_{A}^{*} \geq \pi_{B}^{*}$ : what distinguishes group $A$ from group $B$ is that $A$ wants just as much or more of $\pi$. It is helpful to define the parameter $\alpha \in[0,1]$ as the distance between party $A$ 's and party $B$ 's ideal policies, so that

$$
\alpha=\pi_{A}^{*}-\pi_{B}^{*} .
$$

We can think of $\alpha$ as a measure of political polarization. If $\alpha=0, A$ and $B$ have identical preferences. If, by contrast, $\alpha=1$, their preferences are diametrically opposed. Note that the utility that members of group $J$ derive from the implementation of the other group's ideal policy is $\left(1-\alpha^{2}\right) \omega_{t}$

\section{Political Institutions}

In each period, either $A, B$, or a coalition of the two controls the government. We assume that under power-concentration institutions, all governments are single-party governments (either $A$ or $B$ governs), but under power-sharing institutions, all governments are coalitions ( $A$ and $B$ govern together, with one of them, the agenda setter, having the power to propose policies that the other party must either accept or reject). Under power-concentration institutions, then, the party in power sets policy unilaterally in each period; under power-sharing institutions, all policy changes, relative to the status-quo policy $\pi_{t-1}$, require unanimity.

We assume that the status-quo policy in place in the beginning of period 1 , denoted $\pi_{0}$, is the mean of $A$ 's and $B$ 's ideal policies, so that

$$
\pi_{0}=\frac{1}{2}\left(\pi_{A}^{*}+\pi_{B}^{*}\right) .
$$

The status-quo policy in period 1 is thus equally beneficial to both parties. 
We also assume that under both power-concentration and power-sharing institutions, the probability of political turnover is $\frac{1}{2}$. With probability $\frac{1}{2}$, the group that controls the government (under power-concentrating institutions) or acts as agenda setter (under power-sharing institutions) in period 1 remains in the same position in period 2. Otherwise the other party takes over. This assumption simplifies the exposition greatly, and allowing the rate of political turnover to vary would not change the main message of the paper. ${ }^{10}$

\section{Modeling Crises and Investments}

The main distinction between "crisis management" and "political investments," in our model, is that a crisis requires governments to adjust public policies temporarily to changing circumstances to avoid harm, whereas an investment requires governments to forgo some welfare now in the expectation that welfare will be higher in the future.

Our analysis of crisis management is thus concerned with how governments adjust policies to sudden, adverse events. Specifically, we model a crisis as an event that threatens to reduce permanently the quality of government policy by $h \in(0,1]$ ( $h$ for "harm"). In other words, unless the government in period 1 acts to avert the crisis, $\omega_{2}=\omega_{1}=(1-h) \omega_{0}$. The action that the government can take to avert the crisis is to adopt a policy in period 1 that is equal to or greater than the critical value $\pi_{c}$. The assumption is that circumstances in period 1 require some minimal level of $\pi$ - perhaps because a looming banking crisis requires a higher level of financial regulation or

\footnotetext{
${ }^{10} \mathrm{It}$ is possible to generalize the model by allowing the probability of turnover to vary. Allowing the probability of turnover to be very low would make investments more likely in power-concentration systems (at least for certain values of the parameter $\alpha$ ). A high probability of turnover would have the opposite effect. For most democracies, however, a turnover probability of $\frac{1}{2}$ is a reasonable approximation of the mean rate over time. We have therefore chosen to simplify the analysis in this manner.
} 
because an impending economic crisis begins in a sector of the economy that benefits from a high level of $\pi$. Note that we are modeling a particular type of crisis, in that successfully averting the crisis has an asymmetric distributional impact (a crisis that could be averted by equal sacrifices by both players would typically be averted immediately).

In our analysis of political investments, we assume that there is an opportunity to forgo some welfare in period 1 , temporarily lowering the quality of public policies in that period by $\iota$, with the aim of increasing the quality of public policies, and therefore welfare, to $(1+y) \omega_{1}$ in period 2 . We assume that $\iota$, the cost of making such an investment, is greater than 0 and lesser than $y$ (in other words, we are only modeling investments that in fact lead to a net increase in the quality of public policies over both periods).

\section{Order of Moves}

Since none of our results depend on the value of $\omega_{0}$, we normalize $\omega_{0}$ to 1 .

The order of moves is the following:

(1) Party $J$ adopts (under power-concentration institutions) or proposes (under power-sharing institutions) a policy. The first-period policy vector is $\left\{\pi_{1}\right\}$ in our analysis of crisis management and $\left\{\pi_{1}, \iota\right\}$ in our analysis of political investments. Under power-sharing institutions, the other party either accepts or rejects $J$ 's proposal. If the proposal is rejected, the status quo policy remains in force ( $\pi_{1}=\pi_{0}$ and no investment is made).

(2) In the crisis-management part of the model, if $\pi_{1} \geq \pi_{c}$, the quality of public policy remains constant in $t_{1}$ and $t_{2}\left(\omega_{2}=\omega_{1}=\omega_{0}=1\right)$, otherwise the quality declines to $1-$ $h$ in both periods due to the unchecked crisis (the crisis can only be averted in period 1). In the political-investment part of the model, making the investment reduces the 
quality of public policy in period 1 to $1-\iota$, whereas the quality in period 2 increases to $1+y$.

(3) With probability $\frac{1}{2}$, party $J$ holds on to power (or remains agenda setter) in period 2; with probability $\frac{1}{2}$, the other party wins power (or becomes agenda setter).

(4) The party that is in power (or acts as agenda setter) in period 2 adopts (under powerconcentration institutions) or proposes (under power-sharing institutions) a policy $\pi_{2}$. Under power-sharing institutions, the other party either accepts or rejects the first party's proposal. If the proposal is rejected, the status quo policy remains in force $\left(\pi_{2}=\right.$ $\left.\pi_{1}\right)$.

\section{Crises}

We begin our analysis with the case of crisis management in power-concentration systems.

\section{Power Concentration}

Our main objective is to describe the circumstances in which the party in power in period $1, J$, chooses to avert a crisis.

If $\pi_{J}^{*} \geq \pi_{c}, J$ 's choice in period 1 is simple: whether there is a crisis or not, $J$ 's ideal policy is to set $\pi_{1}$ at level that is sufficiently high to avert a crisis. There is consequently no trade-off between averting a crisis and pursuing other political goals.

If $\pi_{J}^{*}<\pi_{c}$, however, $J$ needs to choose between setting $\pi_{1}$ to a higher level than $J$ would ideally want (in the interest of averting the crisis) or ignoring the crisis and adopting its own ideal policy, $\pi_{J}^{*}$. Comparing $J$ 's expected utility of averting and not averting the crisis, we find that $J$ 's optimal 
choice is to avert the crisis if the harm done by the crisis, $h$, is greater than or equal to the critical value $h_{P C}^{*}$, which is defined by

$$
h_{P C}^{*}=\frac{2\left(\pi_{c}-\pi_{J}^{*}\right)^{2}}{4-\alpha^{2}} .
$$

This critical value has an intuitive interpretation: $J$ is willing to take measures against a crisis if the difference between $\pi_{c}$ and $\pi_{J}^{*}$ is low and if $\alpha$ is low. In other words, $J$ is willing to respond to a crisis if averting the crisis does not require policy measures that $J$ is strongly opposed to and if distributional conflicts are low.

\section{Power Sharing}

We now turn to the case of crisis management in power-sharing systems. In power-concentration systems, as we have just seen, the party in power in period 1 worries about period 2 since the party in power in period 2 is always able to set its ideal policy. In power-sharing systems, by contrast, the parties in period 1 worry about period 2 since the policy adopted in period 1 is also period 2's status quo policy, which makes it possible for that policy to become "locked in." Specifically, any policy $\pi_{1}$ that satisfies

$$
\pi_{A}^{*} \geq \pi_{1} \geq \pi_{B}^{*}
$$

will stand in period 2. Moreover, even if $\pi_{c}>\pi_{A}^{*}$, so that $A$ will always want to lower $\pi$ in period 2, $B$ 's bargaining position will be relatively weak since $A$ will only accept policy changes that satisfy

$$
\left|\pi_{2}-\pi_{A}^{*}\right| \leq\left|\pi_{1}-\pi_{A}^{*}\right| .
$$


If $\pi_{0} \geq \pi_{c}$, policy choices in period 1 are straightforward: since the status-quo policy is sufficient to avert an economic crisis, the status-quo policy always stands (and crises are always averted).

If $\pi_{0}<\pi_{c} \leq \pi_{A}^{*}$, the strategic situation is more interesting. $B$ knows that if $\pi_{1}$ is set to $\pi_{c}$, that policy will always stand in period $2\left(\right.$ since $\left.\pi_{c} \leq \pi_{A}^{*}\right)$. This means that a crisis will only be averted if $B$ expects to be harmed more by the crisis than by raising $\pi$ from $\pi_{0}$ to $\pi_{c}$ in both periods - or, in other words, if $h$ exceeds the critical value $h_{P S 1}^{*}$, which is defined by

$$
h_{P S 1}^{*}=\frac{4\left(\pi_{c}-\pi_{B}^{*}\right)^{2}-\alpha^{2}}{4-\alpha^{2}} .
$$

This condition holds regardless of whether $A$ or $B$ is the agenda setter in period 1 ( $B$, having the most to lose, is the pivotal decision-maker). But the identity of the agenda setter matters for the exact level of $\pi_{1}$ and $\pi_{2}$ if the crisis is averted. If $\mathrm{B}$ is the agenda setter and $h$ exceeds the critical value $h_{P S 1}^{*}, B$ will propose $\pi_{1}=\pi_{c}$ and $A$ will accept. If $A$ is the agenda setter, on the other hand, $A$ is typically able to increase $\pi$ to an even higher level than $\pi_{c}$, since $A$ can propose setting $\pi$ to a level that makes $B$ indifferent between averting and not averting the crisis.

The expression on the right-hand side of equation (2) has some interesting properties. As in the power-concentration case (see equation 1), the crucial decision maker in the government, $B$, is willing to take measures against a crisis if the difference between $\pi_{c}$ and $\pi_{B}^{*}$ is low. But in this particular scenario, $\alpha$, our measure of political polarization, is negatively related with $h_{P S 1}^{*}$. In other words, political polarization now makes it more likely that crises are averted. But note that this scenario, in which $\pi_{0}<\pi_{c} \leq \pi_{A}^{*}$, is more likely to occur when polarization, as defined by $\alpha$, is already high. ${ }^{11}$

11 Note that 
If $\pi_{A}^{*}<\pi_{c} \leq \pi_{A}^{*}+\alpha$, the strategic situation is more interesting still. $B$ knows that if $\pi_{1}$ is set to $\pi_{c}, A$, like $B$, will want to lower $\pi$ when the two groups bargain over policy in period 2, but $A$ will nevertheless be at an advantage, for if $A$ becomes the agenda setter in period 2, $A$ will be able to set its own ideal policy, and if $B$ becomes the agenda setter, it will not be able to propose a policy that is lower than $2 \pi_{A}^{*}-\pi_{c}$ (since A will only accept if the distance between the policy proposal and $A$ 's ideal policy is lesser than or equal to the distance between $A$ 's ideal policy and $\pi_{c}$ ).

This means that the crisis will only be averted if $h$ exceeds the critical value $h_{P S 2}^{*}$, which is defined by

$$
h_{P S 2}^{*}=\frac{3 \alpha^{2}+2 \alpha\left(\pi_{c}-\pi_{A}^{*}\right)+3\left(\pi_{c}-\pi_{A}^{*}\right)^{2}}{4-\alpha^{2}} .
$$

This critical value too has a natural interpretation. $B$ is more likely to accept a policy that reverses the crisis if $\alpha$ is low (that is, if distributional conflicts are not too severe), and if the distance between $\pi_{A}^{*}$ and $\pi_{c}$ is small (the measures required to avert the crisis are not too extreme).

If $\pi_{c}>\pi_{A}^{*}+\alpha$, finally, the measures that are required to avert the crisis are so drastic that both parties prefer the other party's ideal policy to $\pi_{c}$ in period 2 . This means that the critical value of $h$ is

$$
h_{P S 3}^{*}=\frac{2\left(\pi_{c}-\pi_{B}^{*}\right)^{2}}{4-\alpha^{2}}
$$

which, interestingly, is identical to $h_{P C}^{*}$ when $B$ is in power. There is a natural explanation, however: if $B$ wins power in period 2, $B$ can adopt its ideal policy, just as in a power-concentration system. As before, $B$ is more likely to support effective crisis-management measures if $\pi_{c}$ and $\alpha$ are low which is strictly non-positive.

$$
\frac{\partial h_{P S 1}^{*}}{\partial \alpha}=\frac{8 \alpha\left(\left(\pi_{c}-\pi_{B}^{*}\right)^{2}-1\right)}{\left(\alpha^{2}-4\right)^{2}},
$$


(implying that the measures required to avert the crisis are not too extreme and distributional conflicts are not severe).

\section{Equilibrium in the Crisis Game}

Table 1 lists the lower bound for how serious a crisis needs to become for the government to act to avert it in the different versions of our model (the equilibrium behavior of the two parties in all these scenarios is described in full in the Appendix).

Table 1. When Are Crises Averted?

\begin{tabular}{lllll} 
& \multicolumn{2}{l}{ Power Concentration } & \multicolumn{2}{l}{ Power Sharing } \\
\cline { 2 - 5 } Govt./agenda setter: & $A$ & $B$ & $A$ & Always \\
\hline$\pi_{c} \leq \pi_{B}^{*}$ & Always & Always & Always & Always \\
$\pi_{B}^{*}<\pi_{c} \leq \pi_{0}$ & Always & $h \geq h_{P C, B}^{*}$ & Always & $h \geq h_{P S 1}^{*}$ \\
$\pi_{0}<\pi_{c} \leq \pi_{A}^{*}$ & Always & $h \geq h_{P C, B}^{*}$ & $h \geq h_{P S 1}^{*}$ & $h \geq h_{P S 2}^{*}$ \\
$\pi_{A}^{*}<\pi_{c} \leq \pi_{A}^{*}+\alpha$ & $h \geq h_{P C, A}^{*}$ & $h \geq h_{P C, B}^{*}$ & $h \geq h_{P S 2}^{*}$ & \\
$\pi_{c}>\pi_{A}^{*}+\alpha$ & $h \geq h_{P C, A}^{*}$ & $h \geq h_{P C, B}^{*}$ & $h \geq h_{P S 3}^{*}=h_{P C, B}^{*}$ & $h \geq h_{P S 3}^{*}=h_{P C, B}^{*}$
\end{tabular}

Comment: The critical values $h^{*}$ are defined in the text.

On the basis of this table, we can make a direct comparison between power-concentration and power-sharing institutions.

In the special case when $\pi_{B}^{*}<\pi_{c} \leq \pi_{0}$, power-sharing systems are superior to powerconcentrating systems, from a crisis-management perspective, since $B$ sometimes has an incentive not to avert the crisis if $B$ governs alone. In these particular circumstances, the status-quo bias in 
power-sharing systems actually works to their advantage, for the status-quo policy $\pi_{0}$ is sufficient to avert the crisis. ${ }^{12}$

When more drastic measures are required to avert the crisis, however, power-concentration systems are often superior.

Consider first the case where $\pi_{0}<\pi_{c} \leq \pi_{A}^{*}$. In these circumstances, a crisis is always averted when $A$ governs alone, but not always when $A$ is the agenda setter in a power-sharing system. When $B$ is more powerful - governing alone in a power-concentration system or acting as agenda setter in a power-sharing system - the findings are more mixed, but even now power-concentration systems are superior to power-sharing systems, from a crisis-aversion perspective, when the critical value $h_{P S 1}^{*}$ is greater than the critical value $h_{P C, B}^{*}$. By rearranging and simplifying, we find that this is the case when

$$
\alpha<\sqrt{2}\left(\pi_{c}-\pi_{B}^{*}\right)
$$

This suggests that power-concentration systems outperform power-sharing systems when averting the crisis requires more drastic actions (setting $\pi_{c}$ to a high level, bringing it closer to $A$ 's ideal point than $B$ 's). In other words, although governments in power-sharing systems are likely to avert crises that only require small policy adjustments, governments in power-concentrating systems are always more likely to respond to crises that require larger policy adjustments.

If $\pi_{A}^{*}+\alpha \geq \pi_{c}>\pi_{A}$, the crisis is averted under power-concentration if $h>h_{P C}^{*}$ and under power sharing if $h>h_{P S 2}^{*}$. To see whether power-concentration or power-sharing is associated with superior crisis management, we therefore need to compare the critical values $h_{P C}^{*}$ and $h_{P S 2}^{*}$,

\footnotetext{
${ }^{12}$ A "crisis" that can be solved by doing nothing (maintaining the status quo) is hardly severe. Nevertheless, it is an important feature of our model that "small" (in terms of what is required to avert it) crises turn out to be handled more effectively in power-sharing systems than in power-concentrating systems.
} 
and since, even if $B$ is in power (which is the critical case), it is always true that $h_{P C, B}^{*}<h_{P S 2}^{*}$, power-concentration is associated with superior crisis management when $\pi_{c}$ is in this range. ${ }^{13}$

When $\pi_{c}>\pi_{A}^{*}+\alpha$, finally, the crisis is averted under power-concentration if $h>h_{P C}^{*}$ and under power sharing if $h>h_{P S 3}^{*}$, keeping in mind that $h_{P S 3}^{*}=h_{P C, B}^{*}$. It is easy to see that powerconcentration institutions are slightly more likely than power-sharing institutions to avert crises in this scenario, since the critical value $h_{P C, A}^{*}$ is lower than the critical value $h_{P C, B}^{*}$ as long as A and B have different policy preferences.

In general, therefore, power-concentration systems outperform power-sharing systems when it comes to averting crises when averting the crisis requires a relatively large shift in policy; but it is interesting to note that when it comes to crises that only require small policy adjustments, powersharing institutions are sometimes superior.

\section{Investments}

We now proceed to the analysis of investments. As we noted in the introduction, we follow Alan Jacobs $(2011,3-4)$ in defining political investments as "policies that make welfare tradeoffs at the expense of the present and in favor of the future." Such a policy "translates a given amount of short-run welfare into greater long-run welfare." In other words, the total net welfare over all periods is greater if an investment is made than if it is not. As we discussed in Section 1, the main reason that investments are not always made is uncertainty over future policy.

\section{Power Concentration}

\footnotetext{
${ }^{13}$ To see why this is the case, note that $h_{P C}^{*}<h_{P S 2}^{*}$ simplifies to $\alpha+\pi_{A}^{*}-\pi_{c}>0$, which is always true, for in this scenario, we have that $\pi_{A}^{*}+\alpha \geq \pi_{c}>\pi_{A}$.
} 
As before, in a power-concentration system, only one party, $J$, controls the government. In period $1, J$ decides unilaterally whether to invest and sets $\pi_{1}$. If an investment is made, policy quality in period 1 decreases to $1-\iota$, but policy quality in period 2 increase to $1+y$ (as before, we assume that $\left.\omega_{0}=1\right) .{ }^{14}$ With probability $\frac{1}{2}$, the party in power in period 1 stays in power in period 2; with probability $\frac{1}{2}$, power shifts to the other party. The party in power in period 2 then sets $\pi_{2}$.

Since the game ends after period 2, the optimal decision for the party that controls the government in period 2 is always to set its ideal policy. Comparing $J$ 's expected utility of investing with $J$ 's expected utility of not investing, we therefore find that in equilibrium, $J$ 's optimal choice is to make the investment if

$$
y \geq \frac{2 \iota}{2-\alpha^{2}}
$$

Let the right hand-side of this equation define the critical value $y_{P C}^{*}$, which is how much an investment needs to increase policy quality in period 2 for a government in a power-concentration system to undertake it. Whether party $J$, in government in period 1 , makes the investment is thus a function of $\alpha, \iota$, and $y$. Rather intuitively, investments are more likely if distributional conflicts are not divisive, if it is not too costly to make investments, and if the gains of investments are large.

\section{Power Sharing}

Under power-sharing institutions, unanimity is required to adopt new policies. The agenda setter makes a proposal $-\left\{\pi_{1}, l\right\}$ in period 1 and $\left\{\pi_{2}\right\}$ in period 2 -and the other party either accepts or

\footnotetext{
${ }^{14}$ We can think of this as the cost of the investment leading to fewer resources available to keep current quality levels. $\iota$ can be interpreted as the price of quality improvements expressed in units of current quality.
} 
rejects. As before, if the proposition is rejected, the policy $\pi_{t-1}$ remains in place, and no investment is made.

In equilibrium, the investment is always made, since the agenda setter can always propose a policy that includes investments and that makes the other party at least as well off, over two periods, as the status-quo policy. If $A$ is agenda setter in period 1, $A$ proposes making the investment and setting $\pi_{1}$ to a level that is higher than $\pi_{0}$ but nevertheless makes $B$ indifferent between accepting and rejecting $A$ 's proposal. Similarly, if $B$ is the agenda setter, $B$ proposes making the investment and setting $\pi_{1}$ to a level that is lower than $\pi_{0}$.

To see why, consider the case where $A$ is agenda-setter. $A$ 's best strategy is to propose to invest and to propose a policy $\pi_{1}^{\iota} \geq \pi_{0} . B$ accepts if the expected utility associated with $A$ 's proposal is higher than its expected utility of status quo policy $\left(\pi_{0}\right)$, knowing that $\pi_{1}^{\iota}$ will remain in force in period 2. Consider this expression, which defines, implicitly, the value of $\pi_{1}^{\iota}$ that $A$ can propose and that $B$ will accept:

$$
1-\left(\pi_{1}^{\iota}-\pi_{B}^{*}\right)^{2}=\frac{2\left(1-\left(\pi_{0}-\pi_{B}^{*}\right)^{2}\right)}{2+y-\iota} .
$$

Since $y>\iota, A$ is able to set a higher $\pi$ than the status quo, and $B$ will still accept.

The net value of the political investment thus determines the distance between $\pi_{0}$ and the policy that the agenda setter can propose in period 1. To put it differently, the agenda setter can use its agenda-setting power to pay less than an equal share of the cost of the investment in period 1 and to get a relatively larger share of the gains in period 2 . The reason is that both $A$ and $B$ prefer a smaller share of a larger pie if that share is larger - in absolute terms - than a relatively larger share of a smaller pie. 


\section{Equilibrium in the Investment Game}

Under power-concentration institutions, the government always sets its ideal policy $\pi_{J}^{*}$ in both periods. In period 1, the government makes the investment if $y \geq y_{P C}^{*}$; otherwise the government does not make the investment.

Under power-sharing institutions, the investment is always made. The agenda-setter in period 1 proposes a policy that makes the other party indifferent between accepting the proposal and rejecting the proposal, and the other group accepts. The policy adopted in period 1 always stands in period 2.

In sum, power-sharing institutions are superior in the investment game, since the investment is made regardless of the level of distributive conflict and regardless of the level of political uncertainty. Whether investments are made under power-concentration institutions depends on the level of distributional conflict and on the surplus generated by the investment.

\section{The Optimal Constitution}

So far, we have shown that governments in power-concentration systems typically handle crises more effectively than governments in power-sharing systems, especially if the crises can only be averted through major changes in policy, whereas governments in power-sharing systems are more likely to make political investments. This suggests that the optimal constitution, from the perspective of effective government, varies depending on the external context. Powerconcentration systems are more likely to be superior in environments in which crises are common, whereas power-sharing systems are more likely to be superior in environments in which governments need to address long-term investment problems. 
In the model that we have developed, equilibrium behavior by governments depends on several different parameters. In this section, we fix some of the model parameters in order to illustrate the combined effects of three factors: the likelihood of crises relative to the likelihood of investment opportunities, the level of political polarization, and the magnitude of policy changes that are required to avert crises.

To simplify the analysis, we assume that $A$ 's and $B$ 's preferences are inversely related, so that $\pi_{B}^{*}=1-\pi_{A}^{*}$. We also assume that the cost of making an investment, $\iota$, represents a 20 percent reduction of the quality of policies in period 1 (a considerable sacrifice). ${ }^{15}$ The critical values for the harm from a crisis, $h$, and the value of investments, $y$, are determined endogenously using the equations that we derived in the last few sections. ${ }^{16}$

In the four subfigures of Figure 1, the $x$-axis represents the likelihood of a crisis, relative to the likelihood that the government is able to invest in future welfare, whereas the $y$-axis represents the difference between A's and B's political preferences $(\alpha) .{ }^{17}$ The four subfigures themselves represent different levels of $\pi_{c}$, or, in other words, crises that are increasingly difficult to avert. Red areas represent combinations of parameter values for which the aggregate losses associated with power-sharing institutions over both periods of the game are greater than the aggregate losses associated with power-concentration institutions over both periods. Blue areas represent situations

\footnotetext{
${ }^{15}$ Different combinations of values on these parameters generate different patterns. One result that is constant across specifications, however, is that power-concentration systems are only ever superior to power-sharing systems if the likelihood of a crisis is high.

${ }^{16}$ Our calculations regarding the relative performance of power-concentration and power-sharing systems are based on these critical values for $h$ and $y$. In other words, the results that we report concern limiting cases: the maximal harm that an unaverted crisis can cause and the maximal opportunity cost of investments that were not made. An alternative approach would have been to run simulations in which the values of $h$ and $y$ are drawn from some underlying distribution. However, the conclusions of such simulations would have been substantively similar.

${ }^{17}$ The figure is based on the assumption that as long as there is no crisis, it is possible to invest in future welfare. But the results generalize straightforwardly to an environment in which there are sometimes neither crises nor investment opportunities; what matters is the relative likelihood of crises and investment opportunities, not the absolute likelihood.
} 
in which power-concentration institutions are associated with greater aggregate losses than powersharing systems.

As the figure shows, the virtues of power-concentration institutions are most apparent when a major policy shift is required to avert crises ( $\pi_{c}$ is high) and when both the likelihood of crises and the level of distributional conflict $(\alpha)$ are high. For other combinations of parameter values - when only modest policy shifts are required to avert crises, when the risk of crises is low, or when political polarization is low - power-sharing institutions are typically superior. 


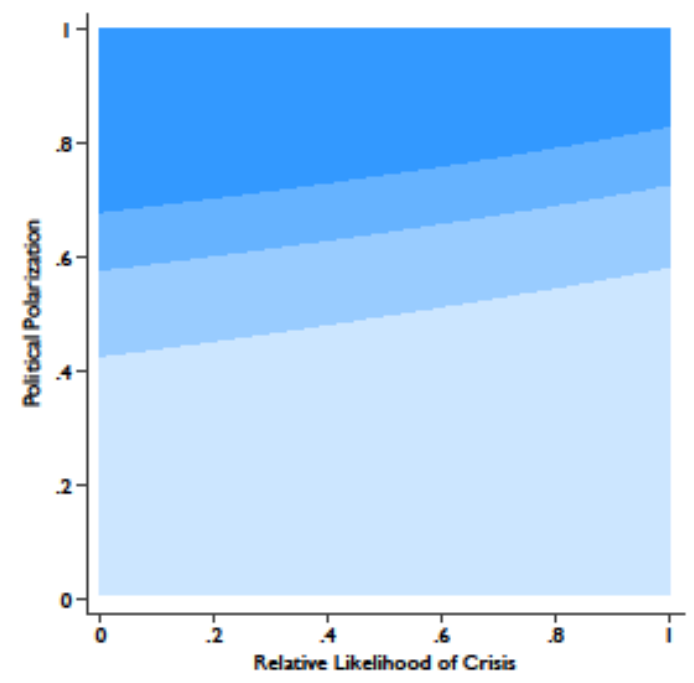

(A) $\pi_{\varepsilon}=0.4$

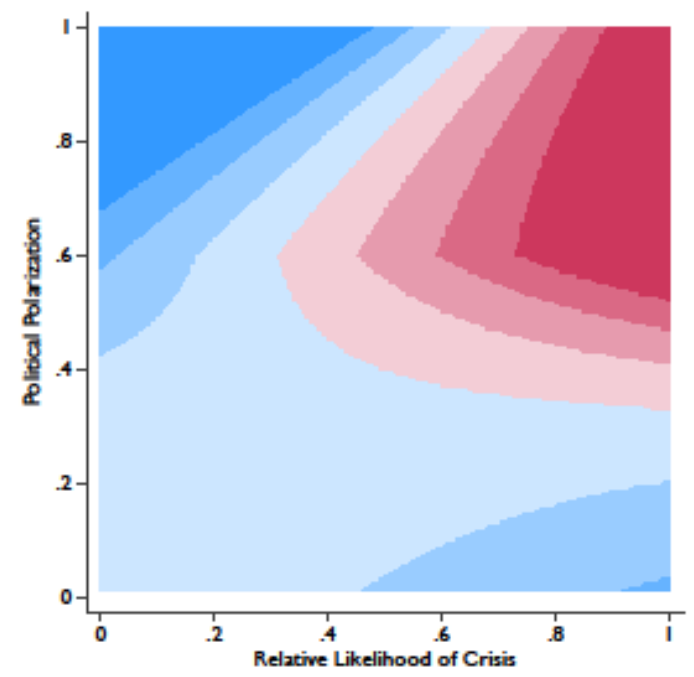

(C) $\pi_{c}=0.8$

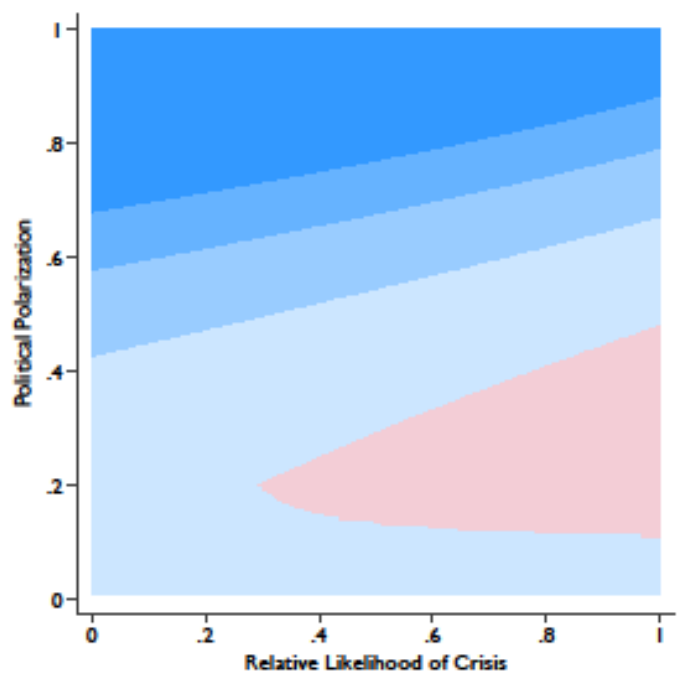

(B) $\pi_{\varepsilon}=0.6$

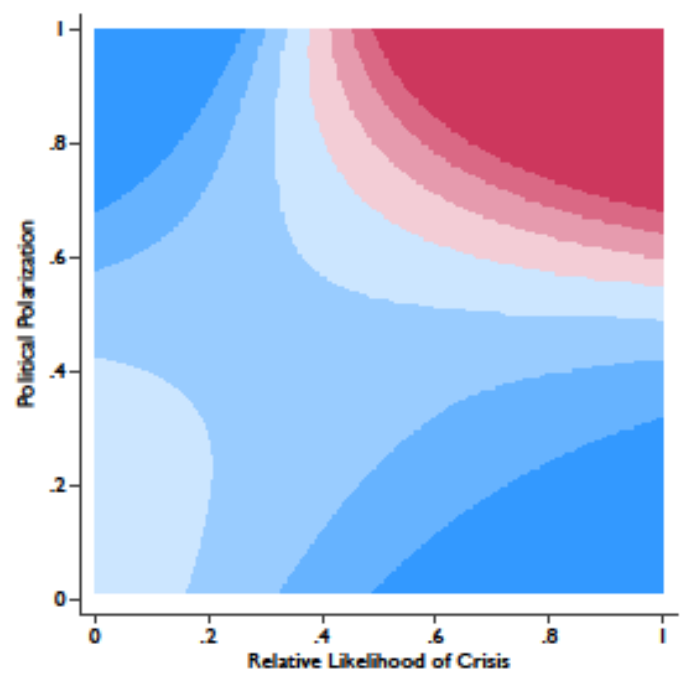

(D) $\pi_{c}=1.0$

Figure 1: The Effects of Institutions. Blue areas represent circumstances in which power-sharing institutions are associated with smaller aggregate losses of policy quality than power-concentration systems, whereas red areas represent circumstances in which power-concentration institutions are associated with smaller aggregate losses of policy quality than power-sharing systems.

\section{Empirical Illustrations}

In the first part of the theoretical analysis, we concentrated on crises, which are situations in which the main challenge for the government is to come up with a quick, resolute policy response to a sudden event. In these circumstances, we argued, power-concentration systems are likely to be 
superior, since crises are averted for a broader range of parameter values in power-concentration systems than in power-sharing systems (at least crises that require a major policy adjustment); power-sharing systems are more sensitive to distributional conflicts.

Consider a country that is faced with a financial crisis. Our model - with its distinction between the elements of public policy that different groups disagree on $(\pi)$ and the public policy objectives that they agree on $(\omega)$ - can be applied straightforwardly to such events. For example, it is easy to imagine that although political parties may agree that the regulation of the financial sector should be of high quality $(\omega)$, they may simultaneously disagree on how much the sector should be regulated $(\pi) \cdot{ }^{18}$ In a financial crisis, moreover, all parties may prefer a temporarily higher level of regulation, as compared to normal times. Even parties that favor light-touch regulation may agree that raising the level of regulation from the status quo level $\pi_{0}$ to a new level $\pi_{c}$ is justified. But parties that favor light-tough regulation will be more reluctant to agree to such policy adjustments if they are concerned that the higher level of regulation will be "locked in" after the crisis, which is a risk they face in power-sharing systems.

This is a plausible explanation for the common empirical finding that power-sharing systems do not counter financial crises as effectively as power-concentration systems. Successful responses to financial crises depend in part on rapid political responses, and the empirical literature on financial crises suggests that in this respect, power-sharing institutions are at a disadvantage (as Alesina and Drazen 1991 and Cox and McCubbins 2001 also argue). Recent research into the political determinants of responses to economic crises shows, for instance, that power sharing impedes effective policy response to both financial crises (O'Keeffe and Tierzi 2015) and banking crises (MacIntyre 2001, Satyanath 2005). Countries with power-sharing institutions also seem to

\footnotetext{
${ }^{18}$ We are grateful to one of the anonymous reviewers for suggesting this application of our model.
} 
react more slowly to fiscal shocks, and therefore generate unsustainable fiscal deficits more quickly (Howitt and Wintrobe 1995, Spolaore 2004). The same logic applies to currency crises. For example, Han (2009) argues, building on Eichengreen and Rose (2001), that swift action is key for a successful defense of a currency peg, and finds that developed countries with a high number of veto players more often fail to defend their currencies than countries in which power is concentrated. Systems with multiple veto players seem to "have difficulty in responding to environmental changes that demand prompt and consistent actions, such as speculative attacks" $\left(\right.$ Han 2009, 730). ${ }^{19}$

The second part of our analysis was concerned with political investments. One important category of political investments is investments in fiscal capacity (see, for example, Besley and Persson 2011, Chapter 2). Fiscal capacity is commonly increased by adding to, reforming, or in other ways changing the tax system. Such reforms are costly. For example, introducing a new tax, such as a tax on income or a Value Added Tax (VAT), requires considerable investments in administrative capacity (Riezman and Slemrod 1987), which matters to politicians with short time horizons even if the investments have large long-term benefits (in the case of the VAT, Keen and Lockwood 2010 argue that the implementation of the VAT required extensive modernization of the tax administration, but led to a more efficient tax system in the long term).

Our model applies to these sorts of political situations as well. Although political parties differ with respect to their preferences over the overall level of taxation, they all benefit from having a more efficient tax system. ${ }^{20}$ But distributional conflicts influence their decisions. When

\footnotetext{
${ }^{19}$ Ha and Kang (2015) examine policy responses to financial crises in developing countries. They find no effect of a crisis on the direction of economic policy in systems with many veto players, indicating a failure to respond to shocks that impeded economic recovery.

${ }^{20}$ Changing or keeping tax rates can also be a strategic response to business cycle shocks or debt crises (see for example Dziuda and Loeper 2017).
} 
governments decide whether to introduce new taxes, increase the levels of existing taxes, or invest in tax administration, they typically do so because they wish to spend the money on specific programs in the future. Uncertainty about future spending priorities therefore matters greatly for the choices that governments make. This uncertainty has been cited as the explanation for why the United States still has no federal broad-based consumption tax (Steinmo 1993), which makes the United States different from other advanced democracies. Our analysis suggests that an investment in a new tax - or in improved tax administration - is more likely to happen in countries where power is shared among several parties than in countries where power is concentrated, since power sharing makes the spending priorities of future governments more predictable. This arguably explains why broad-based VAT taxes were first introduced in proportional democracies such as Denmark in 1967, Germany and Uruguay in 1968, and the Netherlands and Sweden in 1969. ${ }^{21}$

\section{Conclusion}

Our argument is highly stylized. For example, the game-theoretic model has a finite number of time periods. In infinite-horizon repeated games, inter-temporal cooperation is sometimes made possible by trigger strategies, which means that power-concentration systems might perform relatively better if the model were extended to infinite time. In our view, however, an infinitehorizon formulation would have important drawbacks. It is unlikely that political agents in the real world look toward the infinite future, and they are certainly not sure to play the same opponents in

\footnotetext{
${ }^{21}$ An exception is semi-majoritarian France, which introduced the VAT already in 1968 (Carter 2013). Another example of policymaking for the long term is pension reform. The long-term sustainability of pension systems depends on present investments, which are financed by taxes or social-insurance contributions. Jacobs (2011) finds that the decision whether to invest in a reformed pension system depends on the risk that future government will use those funds for other purposes. Our theoretical analysis suggests that this risk is what sometimes renders governments in power-concentration systems unable to solve investment dilemmas.
} 
infinity. Moreover, trigger strategies that are based on the threat of eternal non-cooperation are often not politically credible.

Another simplification in our model is the absence of so-called sunset provisions: policies with a well-defined end date. If a policy response to a crisis can be designed in such a way that it is not permanent, the commitment problem that political agents face in power-sharing systems in our model can be avoided. We believe that the simplification we have made is justifiable, however. Sunset provisions are rare - on the United States, see Dziuda and Loeper 2016, 1171, and the works cited there - and a policy change that is intended to be temporary can easily become permanent if a new constituency forms that is in favor of the new policy. Removing a benefit, once introduced, is typically unpopular.

There are strong reasons to believe, therefore, that whereas power-concentration institutions are typically associated with superior crisis management, at least when major policy adjustments are required to avert crises, power-sharing institutions are associated with a higher likelihood that governments make long-term investments. 


\section{References}

Acemoglu, Daron and James A. Robinson. 2000. "Why Did the West Extend the Franchise? Democracy, Inequality, and Growth in Historical Perspective." The Quarterly Journal of Economics 115 (4):1167-1199.

----2001. “A Theory of Political Transitions.” American Economic Review 91 (4):938-963.

Alesina, Alberto and Allan Drazen. 1991. "Why Are Stabilizations Delayed?” American Economic Review 81 (5):1170-1188.

Alesina, Alberto and Guido Tabellini. 1990. “A Positive Theory of Fiscal Deficits and Government Debt." The Review of Economic Studies 57 (3):403-414.

Besley, Timothy and Torsten Persson. 2011. Pillars of Prosperity. Princeton: Princeton University Press.

Buisseret, Peter and Dan Bernhardt. 2017. "Dynamics of Policymaking: Stepping Back to Leap Forward, Stepping Forward to Keep Back.” American Journal of Political Science.

Carter, Alan. (ed.) 2013. "International Tax Dialogue: Key issues and debates in VAT, SME taxation and the tax treatment of the financial sector." International Tax Dialogue. http://www.itdweb.org.

Cox, Gary W. and Mathew D. McCubbins. 2001. "The Institutional Determinants of Economic Policy Outcomes." In Presidents, Parliaments, and Policy, edited by Stephan Haggard and Mathew D. McCubbins. Cambridge: Cambridge University Press, 21-63.

de Figueiredo Jr., Rui J. P. 2002. "Electoral Competition, Political Uncertainty, and Policy Insulation." American Political Science Review 96 (2):321-333.

Dziuda, Wioletta and Antoine Loeper. 2016. "Dynamic Collective Choice with Endogenous Status Quo.” Journal of Political Economy 124 (4):1148-1186. 
Dziuda, Wioletta and Antoine Loeper. 2017. "Dynamic Pivotal Politics." Working paper.

Eichengreen, Barry and Andrew Rose. 2001. "To Defend or Not to Defend? That is the Question." Unpublished manuscript, University of California, Berkeley, CA.

Fearon, James. 2004. “Why Do Some Civil Wars Last So Much Longer Than Others?” Journal of Peace Research 41 (3):275-301.

Fearon, James D. 1995. "Rationalist Explanations for War." International Organization 49 (3):379-414.

Gehlbach, Scott and Edmund J. Malesky. 2010. "The Contribution of Veto Players to Economic Reform." The Journal of Politics 72 (4):957-975.

Ghosal, Sayantan and Eugenio Proto. 2009. "Democracy, collective action and intra-elite conflict." Journal of Public Economics 93:1078-1089.

Ha, Eunyoung and Myung-koo Kang. 2015. "Government Policy Responses to Financial Crises: Identifying Patterns and Policy Origins in Developing Countries." World Development 68:264281.

Han, Kyung Joon. 2009. "Policy decisiveness and responses to speculative attacks in developed countries." European Journal of Political Research 48 (6):723-755.

Howitt, Peter and Ronald Wintrobe. 1995. "The political economy of inaction.” Journal of Public Economics 56 (3):329-353.

Jacobs, Alan M. 2011. Governing for the Long Term. Democracy and the Politics of Investment. Cambridge: Cambridge University Press.

---- 2016. "Policy Making for the Long Term in Advanced Democracies." Annual Review of Political Science 19:433-454. 
Keen, Michael and Ben Lockwood. 2010. "The value added tax: Its causes and consequences." Journal of Development Economics 92(2):138-151.

Lijphart, Arend. 1977. "Majority Rule versus Democracy in Deeply Divided Societies." Politikon $4(2): 113-126$.

---- 2012. Patterns of Democracy. New Haven: Yale University Press, second ed.

Lindvall, Johannes. 2017. Reform Capacity. Oxford: Oxford University Press.

MacIntyre, Andrew. 2001. "Institutions and Investors: The Politics of the Economic Crisis in Southeast Asia.” International Organization 55 (1):81-122.

O'Keeffe, Mícheál and Alessio Tierzi. 2015. "The Political Economy of Financial Crisis Policy.” Bruegel Working Paper 2015/06, July 2015.

Powell, G. Bingham. 2000. Elections as Instruments of Democracy. New Haven: Yale University Press.

Powell, Robert. 2004. "The Inefficient Use of Power." American Political Science Review 98 (2):231-241.

Riezman, Raymond and Joel Slemrod. 1987. "Tariffs and collection costs." Weltwirtschaftliches Archiv 123 (3):545-549.

Sartori, Giovanni. 1987. The Theory of Democracy Revisited. Chatham, New Jersey: Chatham House.

Satyanath, Shanker. 2005. Globalization, Politics, and Financial Turmoil: Asia's Banking Crisis. Cambridge University Press.

Schmidt, Manfred G. 2002. "Political Performance and Types of Democracy: Findings from Comparative Studies.” European Journal of Political Research 41 (1):147-163. 
Spolaore, Enrico. 2004. “Adjustments in Different Government Systems.” Economics \& Politics $16(2): 117-146$.

Steinmo, Sven. 1993. Taxation and Democracy. New Haven: Yale University Press.

Tommasi, Mariano, Carlos Scartascini, and Ernesto Stein. 2014. "Veto Players and Policy Adaptability." Journal of Theoretical Politics 26 (2):222-248.

Tsebelis, George. 2002. Veto Players. Princeton: Princeton University Press. 


\section{Appendix: Equilibrium in the Crisis Game}

(i) If $\pi_{c} \leq \pi_{B}^{*}$, a crisis is always averted. Under power-concentration institutions, the party that is in power in period 1 adopts its ideal policy $\pi_{J}^{*}$ (which is sufficient to avert the crisis); then the party that is in power in period 2 adopts its ideal policy. Under power-sharing institutions, the status quo policy $\pi_{0}$ remains in force in both period 1 and period 2 and is sufficient to avert the crisis.

(ii) If $\pi_{B}^{*}<\pi_{c} \leq \pi_{0}$, the crisis is always averted, with one exception: power-concentration systems in which $B$ is in government and $B$ has an incentive to adopt its ideal policy rather than averting the crisis. Under power-concentration institutions, $A$, if in government, adopts its ideal policy $\pi_{A}^{*}$, which is sufficient to avert the crisis, whereas $B$, if in government, only adopts the policy $\pi_{c}$ if $h \geq h_{P C}^{*}$, otherwise $B$ adopts its ideal policy $\pi_{B}^{*}$; then the group that is in power in period 2 adopts its ideal policy. Under power-sharing institutions, the status quo policy $\pi_{0}$ remains in force in both period 1 and period 2 and is sufficient to avert the crisis.

(iii) If $\pi_{0}<\pi_{c} \leq \pi_{A}^{*}$, we need to consider several scenarios. Under power-concentration institutions, $A$, if in government, adopts its ideal policy $\pi_{A}^{*}$ (which is sufficient to avert the crisis), whereas $B$, if in government, adopts the policy $\pi_{c}$ if $h \geq h_{P C}^{*}$, otherwise $B$ adopts its ideal policy $\pi_{B}^{*}$ and the crisis is not averted; then the party that is in power in period 2 adopts its ideal policy. Under power-sharing institutions, the status quo policy $\pi_{0}$ remains in force in both period 1 and period 2 (and the crisis is not averted) if $h<h_{P S 1}^{*}$; if $h \geq h_{P S 1}^{*}, A$, if agenda setter, proposes a policy $\pi_{1}$ in the range $\pi_{c} \leq \pi_{1} \leq \pi_{A}^{*}$ that makes $B$ indifferent between averting and not averting the crisis, and $B$ accepts (that policy also stands in period 2), whereas $B$, if agenda setter, proposes $\pi_{1}=\pi_{c}$ and $A$ accepts (and that policy stands in period 2). 
(iv) If $\pi_{A}^{*}<\pi_{c} \leq \pi_{A}^{*}+\alpha$, we also need to distinguish between several scenarios. Under powerconcentration institutions, the party in government adopts the policy $\pi_{c}$ if $h \geq h_{P C}^{*}$, otherwise the party in government adopts its ideal policy $\pi_{J}^{*}$; then the group that is in power in period 2 adopts its ideal policy. Under power-sharing institutions, the status quo policy $\pi_{0}$ remains in force in both period 1 and period 2 (and the crisis is not averted) if $h<h_{P S 2}^{*}$; otherwise the agenda setter proposes $\pi_{1}=\pi_{c}$, and the government in period 2 adopts $\pi_{2}=\pi_{A}^{*}$ (if A is agenda setter) or $\pi_{2}=$ $2 \pi_{A}^{*}-\pi_{c}$ (if $\mathrm{B}$ is agenda setter).

(v) In the final scenario, $\pi_{c}>\pi_{A}^{*}+\alpha$. Under power-concentration institutions, the party in government adopts the policy $\pi_{c}$ if $h \geq h_{P C}^{*}$, otherwise the party in government adopts its ideal policy $\pi_{J}^{*}$; then the group that is in power in period 2 adopts its ideal policy. Under power-sharing institutions, the status quo policy $\pi_{0}$ remains in force in both period 1 and period 2 (and the crisis is not averted) if $h<h_{P S 3}^{*}=h_{P C, B}^{*}$; otherwise the agenda setter proposes $\pi_{1}=\pi_{c}$, and the government in period 2 adopts its ideal policy. 